\title{
Excitatory Synaptic Input to Hilar Mossy Cells under Basal and Hyperexcitable Conditions
}

\author{
(1)Tristan P. Hedrick, ${ }^{1 *}$ (D) William P. Nobis, ${ }^{2^{*}}{ }^{-}$Kendall M. Foote, ${ }^{2}$ (D) Toshiyuki Ishii, ${ }^{1,3}$ Dane M.
} Chetkovich, ${ }^{2,4}$ and ${ }^{\circledR}$ Geoffrey T. Swanson ${ }^{1}$

DOI:http://dx.doi.org/10.1523/ENEURO.0364-17.2017

\begin{abstract}
${ }^{1}$ Department of Pharmacology, Northwestern University Feinberg School of Medicine, Chicago, IL 60611,
${ }^{2}$ Department of Neurology, Northwestern University Feinberg School of Medicine, Chicago, IL 60611, ${ }^{3}$ Department of Physiology, Nippon Medical School, Tokyo 113-8602, Japan, and ${ }^{4}$ Department of Neurology, Vanderbilt University Medical Center, Nashville, TN 37232
\end{abstract}

\section{Visual Abstract}
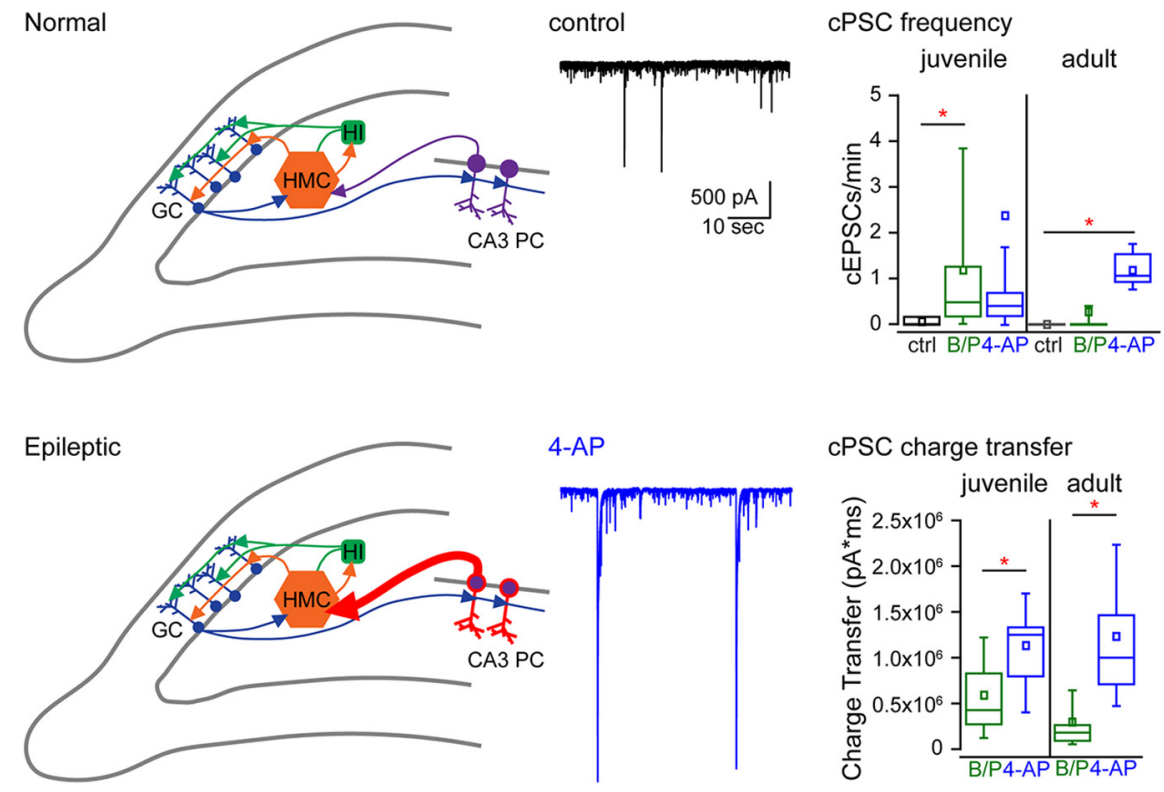

\section{Significance Statement}

Hilar mossy cells (HMCs) constitute a major excitatory principal neuron in the hippocampus with a proposed role in cognitive processing and epilepsy, but many fundamental properties of their excitatory synaptic input have not been characterized. We show that synaptic properties to HMCs from CA3 pyramidal neurons and mossy fibers (MFs) differed in some aspects of their postsynaptic complement of ionotropic glutamate receptors but are surprisingly similar with respect to short-term presynaptic facilitation. In conditions of elevated excitability, the weak but abundant spontaneous input from the CA3 was transformed into large synchronized bursts of excitatory synaptic events. The back-projection from CA3 to mossy cells therefore has the potential to profoundly shape hilar excitability and circuit function in the healthy hippocampal circuit or in pathologic states. 


\begin{abstract}
Hilar mossy cells (HMCs) in the hippocampus receive glutamatergic input from dentate granule cells (DGCs) via mossy fibers (MFs) and back-projections from CA3 pyramidal neuron collateral axons. Many fundamental features of these excitatory synapses have not been characterized in detail despite their potential relevance to hippocampal cognitive processing and epilepsy-induced adaptations in circuit excitability. In this study, we compared preand postsynaptic parameters between MF and CA3 inputs to HMCs in young and adult mice of either sex and determined the relative contributions of the respective excitatory inputs during in vitro and in vivo models of hippocampal hyperexcitability. The two types of excitatory synapses both exhibited a modest degree of short-term plasticity, with MF inputs to HMCs exhibiting lower paired-pulse (PP) and frequency facilitation than was described previously for MF-CA3 pyramidal cell synapses. MF-HMC synapses exhibited unitary excitatory synaptic currents (EPSCs) of larger amplitude, contained postsynaptic kainate receptors, and had a lower NMDA/AMPA receptor ratio compared to CA3-HMC synapses. Pharmacological induction of hippocampal hyperexcitability in vitro transformed the abundant but relatively weak CA3-HMC connections to very large amplitude spontaneous bursts of compound EPSCs (cEPSCs) in young mice ( P20) and, to a lesser degree, in adult mice $(\sim \mathrm{P} 70)$. CA3-HMC cEPSCs were also observed in slices prepared from mice with spontaneous seizures several weeks after intrahippocampal kainate injection. Strong excitation of HMCs during synchronous CA3 activity represents an avenue of significant excitatory network generation back to DGCs and might be important in generating epileptic networks.
\end{abstract}

Key words: aging; CA3; hilus; mossy cell; seizure

\section{Introduction}

Hilar mossy cells (HMCs) are the only hippocampal glutamatergic neurons that are not a component of the classically defined feed-forward trisynaptic circuit (Andersen et al., 1971; Amaral and Witter, 1989). Nonetheless, these large excitatory neurons scattered in the hilar region are an integral component of memory processes such as pattern separation and completion (Scharfman, 1993a; Buckmaster and Schwartzkroin, 1994; Lisman, 1999; Myers and Scharfman, 2009, 2011). HMC circuit function is transduced through afferent synaptic input from dentate granule neurons (via mossy fibers; MFs), CA3 pyramidal neurons, and to a lesser extent from other HMCs and entorhinal cortex neurons (Ishizuka et al., 1990; Frotscher et al., 1991; Scharfman, 1993a,b, 1994b; Wenzel et al., 1997; Larimer and Strowbridge, 2008).

HMCs have largely escaped the extensive interrogation of synaptic function conducted for analogous glutamatergic synapses in the hippocampus (Scharfman, 2016). MF synapses on HMCs are structurally and functionally sim-

Received October 23, 2017; accepted November 10, 2017; First published November 22, 2017.

The authors declare no competing financial interests.

Author contributions: T.P.H., W.P.N., K.M.F., D.M.C., and G.T.S. designed research; T.P.H., W.P.N., K.M.F., and T.I. performed research; T.P.H., W.P.N., K.M.F., and T.I. analyzed data; T.P.H., W.P.N., and G.T.S. wrote the paper.

This work was supported by National Institute of Neurological Disorders and Stroke Grants R21 NS090040 (to G.T.S.) and R01NS059934 (to D.M.C.) and by a Nippon Medical School Grant-in-Aid for Overseas Training (2017) grant funded by the Operating Costs Subsidies for Private Universities (T.I.).

*T.P.H. and W.P.N. contributed equally to this work.

Correspondence should be addressed to Geoffrey T. Swanson, Department of Pharmacology, Northwestern University Feinberg School of Medicine, 303 E. Chicago Avenue, Chicago, IL 60611, E-mail: gtswanson@northwestern.edu. DOI:http://dx.doi.org/10.1523/ENEURO.0364-17.2017

Copyright (C) 2017 Hedrick et al.

This is an open-access article distributed under the terms of the Creative Commons Attribution 4.0 International license, which permits unrestricted use, distribution and reproduction in any medium provided that the original work is properly attributed. ilar to those found on CA3 pyramidal neurons, in that the boutons envelope thorny excrescence-like complex spines on HMC dendrites (Lysetskiy et al., 2005; Nahir et al., 2007; Scott et al., 2008) and, in rats, appear to express similar short- and long-term synaptic plasticity (Lysetskiy et al., 2005). Unlike their connections with CA3 pyramidal neurons, however, MFs also form smaller excitatory synapses on distal simple spines of HMCs (Frotscher et al., 1991; Acsády et al., 1998), raising the possibility that heterogeneous synaptic signaling might be transduced by single MFs. Pre- and postsynaptic functional parameters of CA3-HMC synapses have not been studied in detail (Scharfman, 2007, 2016), despite the intermediary role of these connections in retrograde flow of activity from CA3 to the dentate (Scharfman, 1994b; especially in models of epilepsy Scharfman, 1994a; Scharfman et al., 2001). Paired recordings in rats demonstrated that CA3 pyramidal neurons make monosynaptic connections with HMCs, and that CA3-HMC inputs are sparse and relatively weaker than MF-HMC synapses (Scharfman, 1993a,b, 1994b). CA3-HMC synaptic potentials from prior recordings displayed no facilitation and had a high failure rate, which, along with histologic evidence that these synapses are located on the distal HMC dendrite suggest that the CA3 back-projection plays a limited role in driving HMC activity (Ishizuka et al., 1990; Frotscher et al., 1991; Kunkel et al., 1993; Scharfman, 1993a,b; Li et al., 1994; Scharfman, 1994b). In short, we know comparatively little about excitatory synapses in HMCs despite their relevance to cognitive processing (Scharfman, 2016).

Adaptations in HMC synaptic input might contribute to hyperexcitability in epilepsy. Hilar neurons degenerate to varying degrees in models of temporal lobe epilepsy and in the human disease (Margerison and Corsellis, 1966; Sloviter, 1987; Blümcke et al., 2000; Zhang et al., 2015), and consequent adaptations in synaptic connectivity and function could exacerbate dentate excitability (Sloviter 
et al., 2003; Santhakumar et al., 2005). Synchronized spiking in CA3 propagates to the hilus and thence to the $D G$ in epileptic animals or following application of $G A B A_{A}$ receptor antagonists, suggesting that CA3-HMC synapses have the potential to powerfully entrain HMC spiking under hyperexcitable conditions (Scharfman, 1994a).

This study compares synaptic properties of glutamatergic inputs to HMCs from the DG and CA3 in mice. The chief distinctions we found were that CA3-HMC synaptic currents contained a proportionally larger NMDA receptor component to the EPSC and that kainate receptors were selectively localized to MF inputs, as occurs in CA3. Short-term plasticity of MF-HMC synapses was markedly lower than that at CA3 pyramidal cell synapses. Finally, we determined that synchronized CA3 firing is effectively transmitted to HMCs in the form of large amplitude compound postsynaptic currents in HMCs in both in vitro and in vivo epilepsy models. Our data demonstrates that the balance between excitatory drive to HMCs arising from CA3 and DG changes in the hyperexcitable hippocampus.

\section{Materials and Methods}

\section{Acute slice preparation}

Acute hippocampal slices were prepared from juvenile (P16-P24; average age, P20) or adult (P45-85; average age, P66) C57bl/6 mice of either gender, in accordance with Institutional Animal Care and Use Committeeapproved protocols. Mice were transcardially perfused with ice-cold sucrose-rich slicing ACSF containing $85 \mathrm{mM}$ $\mathrm{NaCl}, 2.5 \mathrm{mM} \mathrm{KCl}, 1.25 \mathrm{mM} \mathrm{NaH}_{2} \mathrm{PO}_{4}, 25 \mathrm{mM} \mathrm{NaHCO}_{3}$, $75 \mathrm{mM}$ sucrose, $25 \mathrm{mM}$ glucose, $10 \mu \mathrm{M}$ DL-APV, $100 \mu \mathrm{M}$ kynurenate, $0.5 \mathrm{mM} \mathrm{Na}$ L-ascorbate, $0.5 \mathrm{mM} \mathrm{CaCl}_{2}$, and $4 \mathrm{mM} \mathrm{MgCl}_{2}$, and oxygenated and equilibrated with $95 \%$ $\mathrm{O}_{2} / 5 \% \mathrm{CO}_{2}$. Following perfusion, mice were quickly decapitated and horizontal slices $(350 \mu \mathrm{m})$ were prepared using a Leica VT1200S vibratome (Leica Biosystems) in sucrose-ACSF. Slices were transferred to a holding chamber containing sucrose-ACSF warmed to $30^{\circ} \mathrm{C}$ and slowly returned to room temperature over the course of 15-30 min. Slices were then transferred to oxygenated ACSF at room temperature containing $125 \mathrm{mM} \mathrm{NaCl}, 2.4$ $\mathrm{mM} \mathrm{KCl}, 1.2 \mathrm{mM} \mathrm{NaH}{ }_{2} \mathrm{PO}_{4}, 25 \mathrm{mM} \mathrm{NaHCO}{ }_{3}, 25 \mathrm{mM}$ glucose, $2 \mathrm{mM} \mathrm{CaCl}$, and $1 \mathrm{mM} \mathrm{MgCl}$ and maintained under these incubation conditions until recording.

\section{Electrophysiological recordings}

Slices were transferred to a recording chamber and continuously perfused with oxygenated ACSF at room temperature $\left(25^{\circ} \mathrm{C}\right)$. HMCs were visually identified using an upright microscope (Axioskop 2 FS Plus, Zeiss; or BX51WI, Olympus) and subsequently used for whole-cell patch clamp recordings with a MultiClamp $700 \mathrm{~A}$ or $700 \mathrm{~B}$ amplifier (Molecular Devices). Borosilicate glass recording electrodes had tip resistances of 4-7 M $\Omega$ and were filled with an internal recording solution containing $95 \mathrm{mM} \mathrm{CSF}$, $25 \mathrm{mM} \mathrm{CsCl}, 10 \mathrm{mM}$ Cs-HEPES, $10 \mathrm{mM}$ Cs-EGTA, $2 \mathrm{mM}$ $\mathrm{NaCl}, 2 \mathrm{mM}$ Mg-ATP, $10 \mathrm{mM}$ QX-314, $5 \mathrm{mM}$ TEA-Cl, and $5 \mathrm{mM}$ 4-aminopyridine (4-AP), $0.2 \%$ (w/v) biocytin, and adjusted to $\mathrm{pH} 7.3$ with $\mathrm{CsOH}$. Whole-cell voltage clamp recordings from HMCs of AMPA receptor-mediated spon- taneous EPSCs (sEPSCs), and evoked EPSCs were made at $-80 \mathrm{mV}$. Series resistance was continuously monitored and compensated $60-70 \%$. Access resistance was monitored continuously throughout the duration of evoked experiments and between blocks during sEPSC recordings. Those experiments in which the access resistance changed by $>20 \%$ were not included in the data analyses. Access resistances ranged between 5 and $25 \mathrm{M} \Omega$, with an average access resistance of $13.2 \pm 0.3 \mathrm{M} \Omega$. Protocols were executed using pClamp9 or pClamp10 software (Molecular Devices) and an A310 Accupulser driving a D53 constant current isolated stimulator (Digitimer). Analysis was performed using Clampfit 10.2 (Molecular Devices) or MiniAnalysis (Synaptosoft).

MF-HMC EPSCs were evoked by electrical stimulation in the subgranular zone using monopolar glass electrodes at a mean stimulus intensity of $62 \pm 6 \mu \mathrm{A}$ with a pulse duration of $20 \mu \mathrm{s}$ and had mean synaptic latencies of 2.5 $\pm 0.1 \mathrm{~ms}$ in juvenile mice $(n=15)$ and $3.1 \pm 0.2 \mathrm{~ms}$ in adult mice $(n=17)$. A total of $1 \mu \mathrm{M}$ DCG-IV was applied at the end of the recordings to verify MF identity (with an inclusion criterion of $>65 \%$ reduction in amplitude). CA3HMC EPSCs were evoked by electrical stimulation in the CA3 pyramidal cell layer at a mean intensity of $48 \pm 4 \mu \mathrm{A}$ with a pulse duration of $20 \mu \mathrm{s}$ and had a mean synaptic latency of $3.6 \pm 0.2 \mathrm{~ms}$ in juvenile mice $(n=24)$ and 3.7 $\pm 0.3 \mathrm{~ms}$ in adult mice $(n=17)$. Both types of recordings were performed in ACSF containing $10 \mu \mathrm{M}$ bicuculline and $50 \mu \mathrm{M}$ picrotoxin. External solution in CA3-HMC EPSC recordings included $1 \mu \mathrm{M}$ DCG-IV to reduce contamination from MF inputs. The paired-pulse (PP) ratio was calculated from peak EPSC amplitudes in response to a pair of electrical stimuli with a $40 \mathrm{~ms}$ interstimulus interval. The tau of the EPSC decay was derived from a weighted average of a dual-component exponential fit of the falling phase of the EPSC. NMDA/AMPA ratios were calculated based on the peak AMPAR-mediated EPSC amplitude measured at $-80 \mathrm{mV}$, and the NMDARmediated EPSC component measured $40 \mathrm{~ms}$ following electrical stimulation at a $+40 \mathrm{mV}$ holding potential, respectively. Unitary EPSCs (uEPSCs) were evoked at MFHMC or CA3-HMC synapses following equimolar substitution of extracellular $\mathrm{Ca}^{+}$with strontium $\left(\mathrm{Sr}^{+}\right)$in ACSF (Bekkers and Clements, 1999). uEPSCs were manually identified within a time window of $50-350 \mathrm{~ms}$ following the electrical stimulus in 15 traces for each recording. Events smaller than $5 \mathrm{pA}$ or with a charge transfer smaller than $200 \mathrm{pA} / \mathrm{ms}$ were excluded from the analysis. Spontaneous PSCs were identified and measured in $60 \mathrm{~s}$ blocks for each drug condition. Events smaller than 20 pA or with a charge transfer smaller than $200 \mathrm{pA} / \mathrm{ms}$ were excluded from the analysis. Compound PSCs (cPSCs) were identified based on a combination of peak amplitude $(>1 \mathrm{nA})$, number of distinct peaks ( $\geq 2$ within $100 \mathrm{~ms}$ ), and total charge transfer $(>100,000 \mathrm{pA} / \mathrm{ms}$ within $2 \mathrm{~s}$ from the start of the event).

In a subset of experiments, CA3 was dissected away from the DG to sever the connection between CA3 pyramidal neurons and HMCs. In these experiments, a single cut was made between the two blades of the dentate 
gyrus using a razor blade. This cut resulted in complete dissection of CA3 from the hilus, however in a minority of slices, the most proximal portion of CA3c was outside of the cut and remained connected to the hilus.

\section{Intrahippocampal kainic acid (KA) injection}

Eight-week-old $\mathrm{C} 57 \mathrm{bl} / 6$ mice were anesthetized with $5 \%$ inhaled isoflurane and placed in a stereotaxic frame (Stoelting), after which the level of anesthetic was decreased to $1-2 \%$ for the remainder of the procedure. Mice were injected unilaterally with either $100 \mathrm{nl}$ sterile saline solution $(0.9 \%$ saline) or $100 \mathrm{nl} \mathrm{KA}(20 \mathrm{mM} \mathrm{KA}$ diluted in saline solution) into the dorsal hippocampus using a $5 \mu l$ Hamilton syringe (injection coordinates relative to bregma: $2.3 \mathrm{~mm}$ posterior, $1.3 \mathrm{~mm}$ lateral, $1.7 \mathrm{~mm}$ deep; Hubbard et al., 2016). The injection syringe was maintained in the hippocampus for 5 min following the injection and then slowly removed. Mice were administered subcutaneous saline solution and consistently monitored following injections. All mice that received KA injections experienced status epilepticus, defined as three or more hours of continuous seizures classified as stage 3-5 on a modified Racine Scale (Racine, 1972).

\section{EEG recordings and $\mathrm{HMC}$ recordings following $\mathrm{KA}$ injection}

One week following intrahippocampal injection, EEG and EMG electrodes (Pinnacle Technology) that allow two channel EEG and one channel EMG recording were implanted into three KA-injected mice and three salineinjected mice as described previously (Heuermann et al., 2016). Two weeks following intrahippocampal injection and one week following EEG implantation, continual EEG recordings were obtained for 3-6 d, $24 \mathrm{~h} / \mathrm{d}$ using PAL8200 software (Pinnacle Technology). Seizures were detected manually by scrolling through $60 \mathrm{~s}$ epochs of EEG data and identified as high-frequency sharp-wave activity with a duration of at least $10 \mathrm{~s}$ and an amplitude of at least twice the baseline EEG amplitude. HMCs were recorded as described above in acute slices from mice unilaterally injected with either KA or saline (six mice injected with KA, five mice injected with saline).

\section{Identification of HMCs}

HMCs were selected for recording based on the presence of a large, multipolar soma in the hilus. After achieving whole-cell configuration, HMCs were verified by a large whole-cell capacitance $(>45 \mathrm{pF})$, and high frequency of sEPSCs $(>5 \mathrm{~Hz})$. In a subset of recordings, HMCs were filled with biocytin through the recording pipette and identified using post hoc streptavidin staining (56 cells were recovered and stained for morphologic identification out of a total of 179 recorded cells filled with biocytin; 55 of 56 were confirmed to be mossy cells morphologically). Acute slices were fixed following recording in $4 \%$ paraformaldehyde overnight, then stained with streptavidin (Streptavidin Alexa Fluor 594 conjugate; Life Technologies). Images of filled HMCs were obtained using an Olympus FV10 ASW 3.1 confocal microscope (60× objective; NA: 1.35). HMC identity was verified by the presence of thorny excrescences, or "moss," on the proximal dendrites. A total of 55 of 56 neurons that were recovered (98\%) were positively identified as HMCs based on the presence of thorny excrescences (Scharfman and Myers, 2012).

\section{Experimental design and statistical analysis}

The number of animals used and the number of cells evaluated are noted in the results section for each experiment. Animals of either sex were used during this study and potential sex-specific differences were evaluated. Unless otherwise noted, unpaired $t$ tests were used to determine statistical significance. Mean \pm SEM is provided throughout the text. All box and whisker plots are represented as mean, median, interquartile range, and 10-90 percentiles.

\section{Results}

\section{Relative strengths of CA3-HMC and MF-HMC synapses}

The relative strengths of the two primary sources of excitatory synaptic input to HMCs and to what extent those parameters change during maturation is unknown. For those reasons, we compared measures of pre- and postsynaptic function between CA3-HMC and MF-HMC synapses in both juvenile (P16-P24; average age, P20) and adult (P45-P85; average age, P68) mice. Representative traces are shown in Figure $1 A$, with the heavier traces representing the average of the individual events shown in gray. CA3-HMC EPSCs were evoked by electrical stimulation of the CA3c pyramidal layer and had mean amplitudes of $163 \pm 20 \mathrm{pA}$ in neurons from juvenile mice $(n=27)$ as compared to $194 \pm 36 \mathrm{pA}(n=24)$ in mature animals (Fig. $1 A, B$ ). MF-HMC EPSCs were evoked by electrical stimulation of the subgranular zone and had mean amplitudes of $807 \pm 101 \mathrm{pA}$ in juvenile mice $(n=$ $24)$ and $961 \pm 120 \mathrm{pA}$ in adult mice $(n=28)$; with slightly increased stimulus intensity, EPSCs of $>1 \mathrm{nA}$ were frequently recorded (Fig. 1A,B). All MF-EPSCs in this dataset met our criterion of $>65 \%$ reduction in amplitude by DCG-IV $(1 \mu \mathrm{M})$. Decay kinetics of MF-HMC EPSCs were faster on average than those at CA3-HMC synapses, and in neither case was there a difference between neurons in juvenile and adult mice (CA3-HMC EPSC $\tau_{\text {decay }}$ in juvenile mice: $10.3 \pm 1.3 \mathrm{~ms}, n=8$; adult mice: $8.6 \pm 0.9 \mathrm{~ms}, n=$ $12, p=0.58$; MF-HMC EPSC $\tau_{\text {decay }}$ in juvenile mice: $8.6 \pm$ $0.6 \mathrm{~ms}, n=15$; adult mice: $8.7 \pm 0.9 \mathrm{~ms}, n=18, p=$ 0.88 ; Fig. $1 A, C)$. There was no difference in the fast or slow components of the decay at CA3-HMC or MF-HMC synapses (CA3-HMC EPSC $\tau_{\text {decay }}$ in juvenile mice: $\tau_{\text {fast }} 2.5$ $\pm 0.8 \mathrm{~ms}, \tau_{\text {slow }} 17.3 \pm 4.5 \mathrm{~ms}, n=8$; adult mice: $\tau_{\text {fast }} 4.5$ $\pm 0.8 \mathrm{~ms}, \tau_{\text {slow }} 30.6 \pm 7.3 \mathrm{~ms}, n=12, p=0.10$ and $p=$ 0.10 , respectively; MF-HMC EPSC $\tau_{\text {decay }}$ in juvenile mice: $\tau_{\text {fast }} 4.3 \pm 0.7 \mathrm{~ms}, \tau_{\text {slow }} 32.7 \pm 8.4 \mathrm{~ms}, n=15$; adult mice: $\tau_{\text {fast }} 4.6 \pm 0.7 \mathrm{~ms}, \tau_{\text {slow }} 38.3 \pm 10.2 \mathrm{~ms}, n=17, p=0.82$ and $p=0.67$, respectively). Thus, on average CA3-HMC EPSCs were of smaller mean amplitude (at roughly equivalent stimulation strengths, $p<0.001$ both juvenile and adult) compared to MF-HMC EPSCs, and had slightly slower decay kinetics ( $p=0.07$ juvenile, $p=0.02$ adult). No clear differences in the properties of juvenile and adult EPSCs were noted at either synapse. 
A

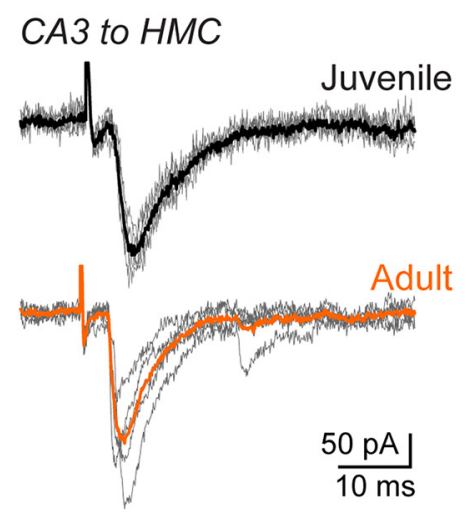

Mossy fiber to HMC

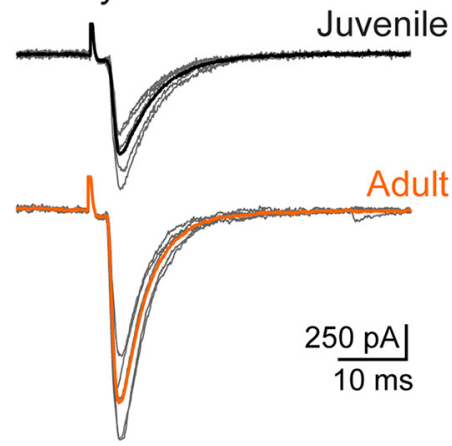

D Unitary EPSCs

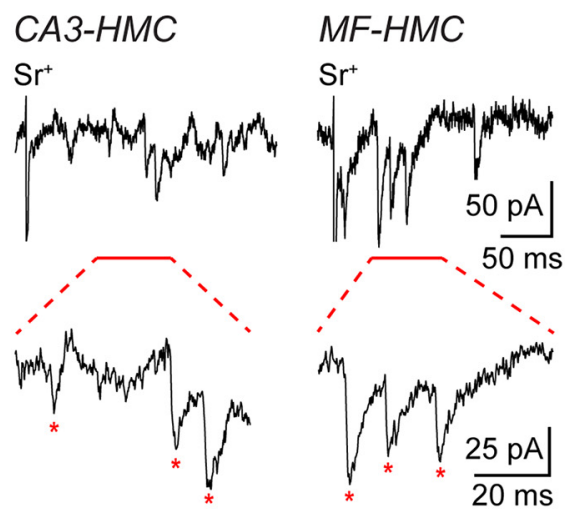

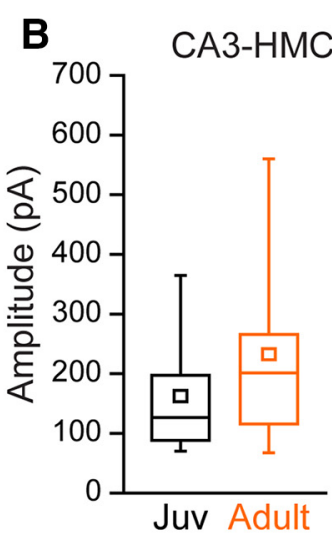

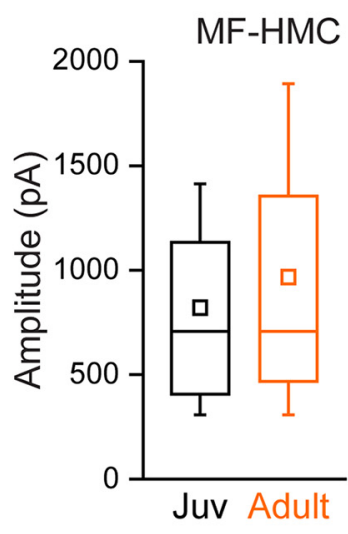

C
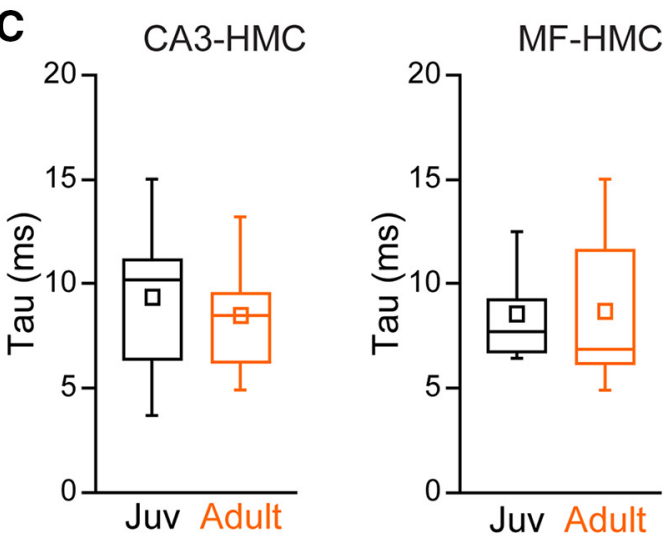

$\mathbf{E}$

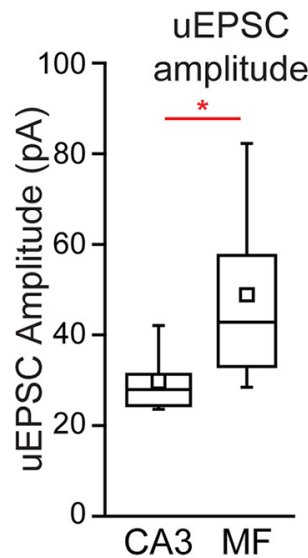

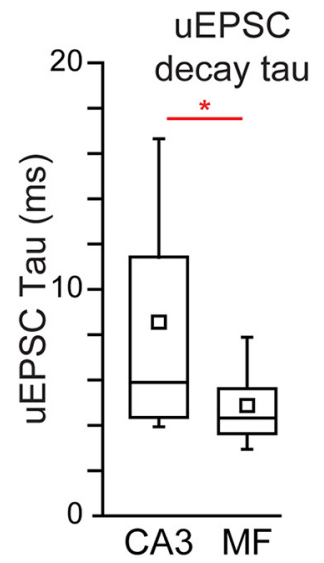

Figure 1. Evoked EPSCs at excitatory HMC afferent synapses. $\boldsymbol{A}$, top, Example EPSCs at a CA3-HMC synapse from whole-cell recordings of HMCs in acute slices from juvenile and adult animals. Bottom, Example EPSCs at a MF-HMC synapse from whole-cell recordings of HMCs in acute slices from juvenile and adult animals. Gray, individual sweeps; black, average trace juvenile; orange, average trace adult. $\boldsymbol{B}$, Amplitude of evoked EPSCs in acute slices from juvenile (black) and adult (orange) mice. Left, CA3-HMC synapse. Right, MF-HMC synapse. Decay kinetics in juvenile and adult mice. $\boldsymbol{C}$, Decay kinetics in juvenile and adult mice. Left, CA3-HMC synapse. Right, MF-HMC synapse. $\boldsymbol{D}$, Example recordings of evoked uEPSCs from CA3-HMC synapses (left) and MF-HMC synapses (right). $\boldsymbol{E}$, Amplitude and decay kinetics of uEPSCs at CA3-HMC (left) and MF-HMC synapses (right). $* p<0.05$.

To determine the relative quantal amplitude of the two synapses, we measured uEPSCs in HMCs in the presence of $2 \mathrm{mM} \mathrm{Sr}^{+}$to desynchronize vesicular release from juvenile mice (Fig. 1D). uEPSC amplitudes were measured during a time window of $50-350$ ms following stimulation. CA3-HMC uEPSCs had a mean amplitude of $29 \pm 2 \mathrm{pA}$ ( $n$ $=10$ recordings from three animals) and decayed with a time constant of $8.6 \pm 1.7 \mathrm{~ms}(n=9$ recordings from three 
A CA3-HMC NMDA/AMPA ratio

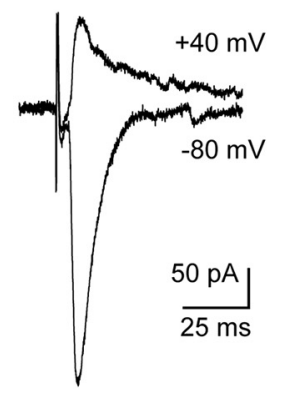

B CA3-HMC EPSCs

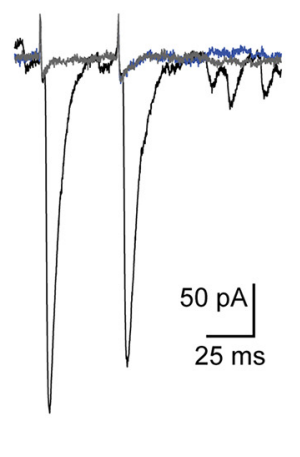

C MF-HMC NMDA/AMPA ratio

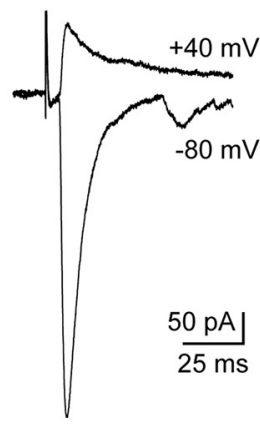

D MF-HMC EPSCs
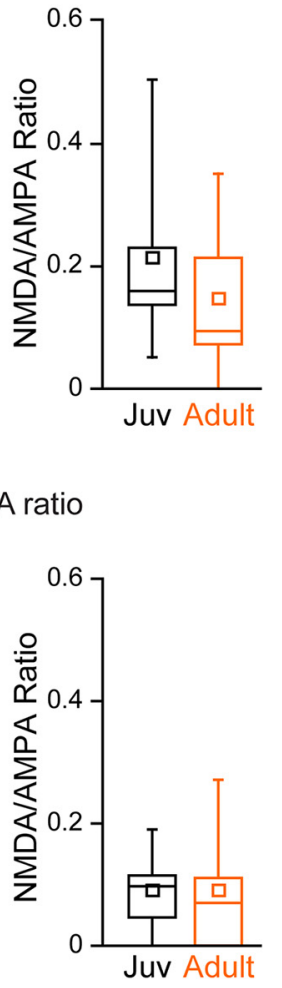

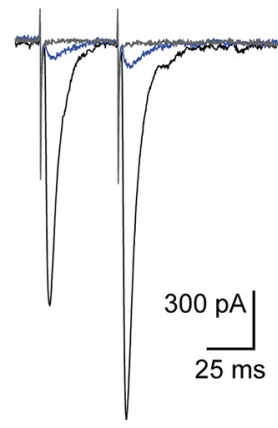

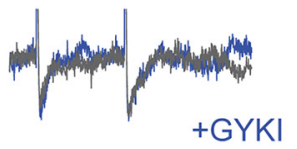

+ CNQX

$25 \mathrm{pA}$

Figure 2. Postsynaptic receptor identity at excitatory HMC afferent synapses. $\boldsymbol{A}$, Example EPSCs recorded from a CA3-HMC synapse while holding the HMC at $-80 \mathrm{mV}$ (lower trace) and $+40 \mathrm{mV}$ (upper trace). Population data showing NMDA/AMPA ratios at CA3-HMC synapses in juvenile (black) and adult (orange) mice. B. Example EPSCs recorded at CA3-HMC synapses (black), following addition of GYKI53655 (KAR-mediated component; blue), and following addition of CNQX (glutamate receptors blocked; gray). Expanded traces shown to the right. C, Example EPSCs recorded from a MF-HMC synapse while holding the HMC at -80 mV (lower trace) and $+40 \mathrm{mV}$ (upper trace). Population data showing NMDA/AMPA ratios at MF-HMC synapses in juvenile (black) and adult (orange) mice. $\boldsymbol{D}$, Example EPSCs recorded at MF-HMC synapses (black), following addition of GYKI53655 (KAR-mediated component; blue), and following addition of CNQX (glutamate receptors blocked; gray). Expanded traces shown to the right.

animals; average number of recorded uEPSCs for each CA3-HMC recording was $69 \pm 10$; Fig. $1 D, E$ ). MF-HMC uEPSCs were of larger mean amplitude, $49 \pm 6 \mathrm{pA}(n=11$ recordings from three animals; $p=0.011$ ) and decayed faster with a $\tau$ of $4.8 \pm 0.6 \mathrm{~ms}(n=12$ recordings from three animals; $p=0.032$; average number of recorded uEPSCs for each MF-HMC recording was $75 \pm 9$ ) than CA3-HMC uEPSCs (Fig. 1D,E). The amplitude of MF-HMC uEPSCs was similar to those described previously for MF-CA3 synapses (Lawrence et al., 2004; Marchal and Mulle, 2004). These data suggest that our standard stimulus strength in normal ACSF (Fig. 1) evoked fewer inputs from CA3 $(\sim 5)$ than MFs from DG $(\sim 16)$.

\section{Postsynaptic glutamate receptor content at excitatory HMC synapses}

MF synapses on CA3 pyramidal neurons have a number of distinct postsynaptic features that are relatively unusual in the CNS, including the expression of postsynaptic kainate receptors (Scharfman and Schwartzkroin, 1988) and a relatively low NMDA/AMPA ratio (Scott et al., 2008); to what extent MF-HMC synapses share these features is unknown. We therefore compared the contributions of different glutamate receptor subtypes to EPSCs at CA3-
HMC and MF-HMC synapses. The AMPA receptor component was measured as the EPSC amplitude at $-60 \mathrm{mV}$; the NMDA receptor component as the current amplitude $40 \mathrm{~ms}$ after stimulation while holding the $\mathrm{HMC}$ at $+40 \mathrm{mV}$.

The NMDA/AMPA ratio at CA3-HMC synapses was $0.22 \pm 0.06$ ( $n=9$ cells from six juvenile animals), with NMDA currents not detected in one out of nine recordings. In adult neurons, the NMDA/AMPA ratio was $0.15 \pm$ 0.04 ( $n=15$ from seven animals), with currents in two recordings lacking a detectable NMDA component (Fig. $2 A)$. The AMPA receptor noncompetitive antagonist GYKI 53655 completely eliminated EPSCs at CA3-HMC synapses $(n=7)$, suggesting that postsynaptic kainate receptors are absent at this synapse (Fig. 2B). NMDA/AMPA ratios at MF-HMC synapses were lower than those at CA3-HMC synapses and a larger proportion lacked a detectable NMDA EPSC (MF-HMC: juvenile mice, $0.09 \pm$ $0.02, n=14$ from 10 animals, with NMDA components not detected in two recordings; adult mice, $0.09 \pm 0.03, n$ $=16$ from nine animals, no NMDA component in six recordings; Fig. 2C). MF-EPSCs clearly contained a kainate receptor EPSC (EPSC KA ); addition of GYKI 53655 revealed a small residual current with kinetics similar to but somewhat faster than those previously recorded at 


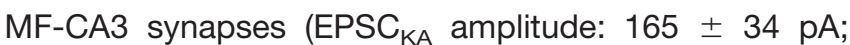
$\tau_{\text {decay }}$ was $25.1 \pm 6.2 \mathrm{~ms}, n=29$ from 13 animals; Fig. $2 D$; Sloviter, 1989). HMCs therefore parallel CA3 pyramidal neurons in their specific localization of postsynaptic kainate receptors to MF but not at CA3 collateral synapses.

\section{Short-term plasticity of excitatory HMC synapses}

Excitatory synapses on CA3 pyramidal neurons are strikingly divergent in their presynaptic function; MF boutons are unusual in their capability to undergo rapid and profound increases in release probability in response to elevated frequencies of stimulation, which in part underlies their proposed role as "detonator" synapses (Henze et al., 2000), whereas CA3 collateral synapses are more conventional in their synaptic function. To determine whether these differential properties are shared by synapses on HMCs, two forms of short-term plasticity, PP and low-frequency facilitation, were compared in wholecell HMC recordings. Paired stimuli with a $40 \mathrm{~ms}$ interval (PP40) facilitated EPSC amplitudes at both synapses to an equivalent degree [CA3-HMC: juvenile, $2.0 \pm 0.1, n=$ 26 from 10 animals; adult, $1.7 \pm 0.2, n=22$ from 13 animals, $p=0.19$ (Fig. 3A); MF-HMC: juvenile, $1.7 \pm 0.1$, $n=24$ from eight animals; adult, $1.7 \pm 0.4, n=17$ from 13 animals, $p=0.90$ (Fig. 3B)].

To determine how these excitatory synapses responded to longer trains of lower frequency stimuli, we evoked EPSCs at 1,5 , and $10 \mathrm{~Hz}$ in trains of 30 stimuli. Again, there was very little difference in presynaptic facilitation between the two synapses (CA3-HMC facilitation: $1 \mathrm{~Hz}, 203 \pm 32 \%, n=11, p=0.010 ; 5 \mathrm{~Hz}: 266 \pm 68 \%$, $n=15, p=0.014 ; 10 \mathrm{~Hz}: 258 \pm 70, n=13, p=0.028$; paired $t$ tests vs pre-tetanus control amplitudes; Fig. $3 C, D)$. EPSC s at MF-HMC synapses facilitated to a similar degree in response to trains of stimuli $(1 \mathrm{~Hz}: 176 \pm 24 \%$, $n=11, p=0.010 ; 5 \mathrm{~Hz}: 201 \pm 27 \%, n=10, p=0.004$; $10 \mathrm{~Hz}: 172 \pm 25 \%, n=10, p=0.005$; Fig. $3 E, F)$. The relatively modest facilitation at these low frequencies observed at MF-HMC synapses was surprising given the relatively large facilitation seen at anatomically similar MF-CA3 synapses (MF-CA3: $1 \mathrm{~Hz}, 313 \pm 34 \%, p=$ $0.014,5 \mathrm{~Hz}: 525 \pm 270 \%, p=0.015,10 \mathrm{~Hz}, 661 \pm 426 \%$, $p=0.0 .018, n=3$ from two animals; Salin et al., 1996; Contractor et al., 2001) and a previous report that concluded MF synapses on the two types of cells exhibited comparable degrees of short-term plasticity (Lysetskiy et al., 2005).

\section{cPSCs in HMCs are evoked by application of proconvulsants in acute slices}

In our recordings of evoked EPSCs, we noted the presence of large-amplitude compound EPSCs (cEPSCs) that occurred spontaneously. These bore similarities to burst discharges previously recorded from epileptic rats, which were proposed to arise from synchronized firing in the highly recurrent CA3 network propagating through the hilus and to dentate granule cells (Scharfman, 1994a; Myers and Scharfman, 2009, 2011; Scharfman et al., 2001). To determine whether the cEPSCs in our recordings were indeed manifestations of CA3-driven synchronized firing, we recorded sEPSCs in HMCs and compared the frequency of compound bursts in control and disinhibited conditions in neurons from both juvenile and mature animals. cEPSCs were defined as superimposed bursts of sEPSCs with a peak burst amplitude $>1 \mathrm{nA}, \geq 2$ superimposed EPSCs within $100 \mathrm{~ms}$, and a total charge transfer of $>100,000 \mathrm{pA} / \mathrm{ms}$ within $2 \mathrm{~s}$ from the start of the event; Fig. $4 A, B$ ). Application of GABA receptor antagonists (bicuculline and picrotoxin) resulted in cEPSCs in juvenile HMCs with a mean charge transfer $596 \pm 96$ $\mathrm{nA} / \mathrm{ms}$ ( $n=180$ events from 18 cells from 12 animals), composed of multiple discrete EPSC peaks, lasted for hundreds of milliseconds before returning to baseline and were eliminated by application of CNQX ( $n=3$ from two animals; data not shown) and, thus, likely arose from summed AMPAR-mediated EPSCs (HMCs in 10 of 12 disinhibited slices from seven animals displayed cEPSCs; Fig. $4 A, C, D$ ). Compound bursts of synaptic events (cPSCs, comprised of both IPSCs and EPSCs) also were recorded when inhibition was intact but intrinsic neuronal excitability was enhanced with the proconvulsant 4-AP (cPSC frequency in ACSF: $0.07 \pm 0.03 \mathrm{cPSC} / \mathrm{min}$; in 4-AP: $2.39 \pm 2.02 \mathrm{cPSC} / \mathrm{min}, p=0.050$; HMCs in 9 of 11 slices from five animals displayed cPSCs after addition of 4-AP; in disinhibited slices: $1.20 \pm 0.49$ cEPSC/min; Fig. $4 B-D$ ). Surprisingly, application of muscarinic acetylcholine agonist pilocarpine did not lead to the generation of cPSCs in HMCs (no cPSCs in three slices from two animals). cPSCs were somewhat rhythmic in their occurrences, in that the interevent-intervals (IEls) had a low coefficient of variation (average CV of IEls in disinhibited slices: $0.45 \pm 0.19, n=7$; CV of IEls in 4-AP: $0.49 \pm 0.17$, $n=9$ ). Thus, cPSCs in HMCs were evoked by hippocampal disinhibition or broad depolarization, but not by activation of muscarinic acetylcholine receptors.

To determine whether mice exhibit a maturational difference in generation of compound synaptic currents, their frequency in recordings from slices from adult mice was compared to the previous data from juvenile neurons. cEPSCs in the presence of GABA receptor antagonists were observed only rarely in slices from adult mice (two of 13 recordings from nine adult mice exhibited cESPCs at a frequency of $0.29 \pm 0.26$ per minute), which was proportionally less common than juvenile HMCs (10 of 12 recordings from seven animals) and less frequent (1.20 \pm 0.49 cEPSC/min in those HMCs with events, $p=0.047$; Fig. 4C). Although cEPSCs were rarely observed in recordings from adult neurons, the charge transfer in those that were generated was similar to that in juvenile neurons $[280 \pm 105 \mathrm{nA} / \mathrm{ms}$ in adult mice, $n=38$ events from 13 cells from nine animals (Fig. 4D); as compared to $596 \pm$ $96 \mathrm{nA} / \mathrm{ms}$ in juvenile mice, $n=180$ events from 18 cells from 12 animals]. Thus, the hippocampal circuit in the adult mouse appears less prone to pathologic synchrony in disinhibited conditions than in juvenile mice. Elevation of network excitability with 4-AP, in contrast, led to the generation of cPSCs in acute slices from both juvenile and adult mice with an occurrence and frequency that was not statistically different from recordings in juvenile mice (six of six recordings from three mice with a frequency of 1.18 $\pm 0.19 \mathrm{cPSCs} / \mathrm{min}$ in adult mice; Fig. 4 C). cPSCs evoked 
A CA3-HMC EPSC pairs

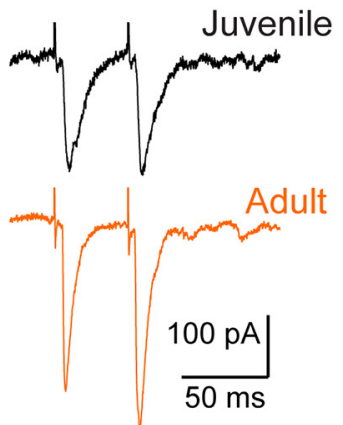

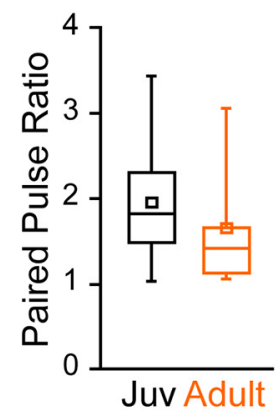

B MF-HMC EPSC pairs

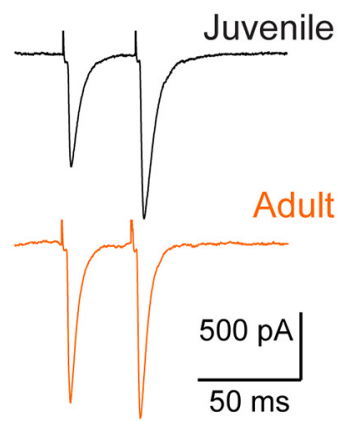

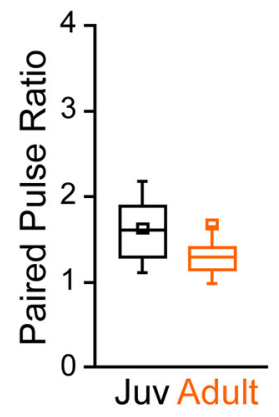

C CA3-HMC frequency facilitation

D CA3-HMC
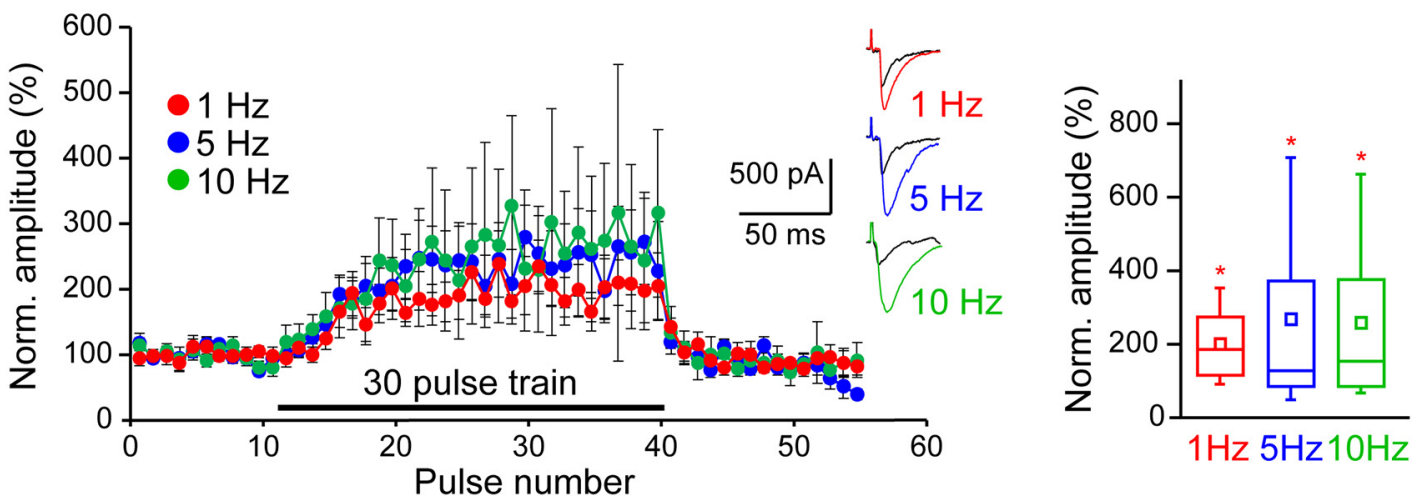

E MF-HMC frequency facilitation

F MF-HMC
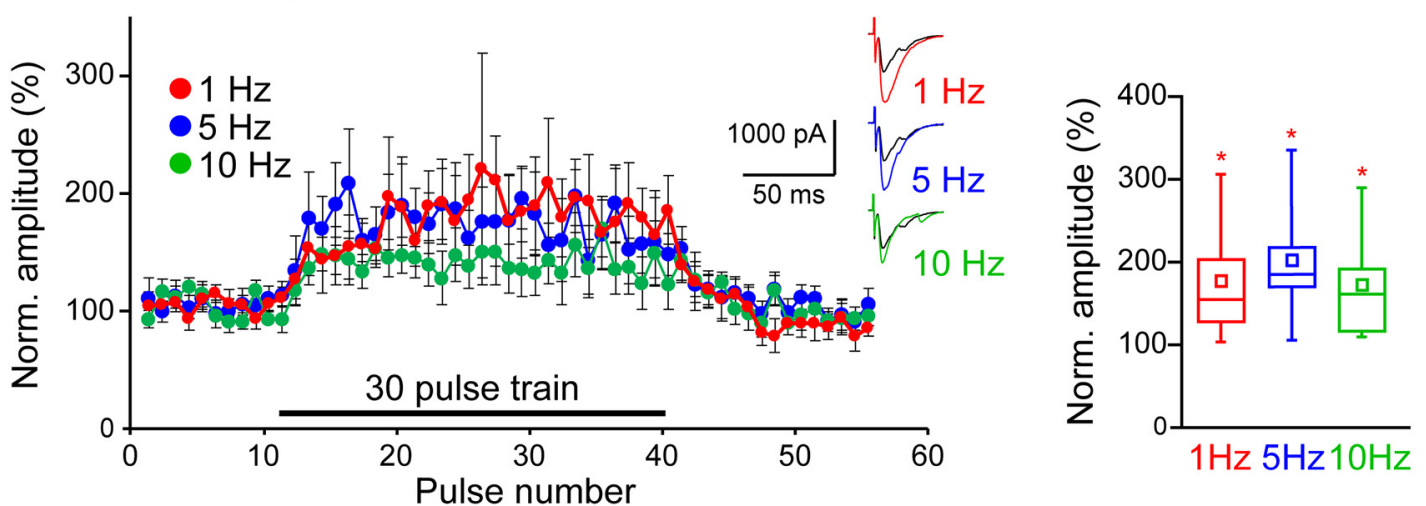

Figure 3. Short-term plasticity at excitatory HMC afferent synapses. A, Example traces showing EPSCs at CA3-HMC synapses in response to paired stimuli $40 \mathrm{~ms}$ apart from juvenile (black) and adult (orange) mice. Population data showing paired pulse ratio at CA3-HMC synapses for paired stimuli at a $40 \mathrm{~ms}$ interval in juvenile and adult mice. $\boldsymbol{B}$, Example traces showing EPSCs at MF-HMC synapses in response to paired stimuli $40 \mathrm{~ms}$ apart from juvenile (black) and adult (orange) mice. Population data showing paired pulse ratio at MF-HMC synapses for paired stimuli at a $40 \mathrm{~ms}$ interval in juvenile and adult mice. $\boldsymbol{C}$, Population data showing the time course of facilitation at CA3-HMC synapses during a train of 30 stimuli at different stimulation frequencies. Example traces showing baseline EPSC amplitude (black) and EPSC amplitude during stimulus trains at $1 \mathrm{~Hz}$ (red), $5 \mathrm{~Hz}$ (blue), and $10 \mathrm{~Hz}$ (green) frequencies. D, EPSC facilitation at CA3-HMC synapses given trains of stimuli at different frequencies. Average facilitation for each cell measured from pulse number 15-20. $\boldsymbol{E}$, Population data showing the time course of facilitation at MF-HMC synapses during a train of 30 stimuli at different stimulation frequencies. Example traces showing baseline EPSC amplitude (black) and EPSC amplitude during stimulus trains at $1 \mathrm{~Hz}$ (red), $5 \mathrm{~Hz}$ (blue), and $10 \mathrm{~Hz}$ (green) frequencies. $\boldsymbol{F}$, EPSC facilitation at MF-HMC synapses given trains of stimuli at different frequencies. Average facilitation for each cell measured from pulse number 5-10. $* p<0.05$.

by 4-AP application in acute slices prepared from adult mice had a charge transfer of $1234 \pm 376 \mathrm{nA} / \mathrm{ms}(n=88$ events), which was similar to $1177 \pm 224 \mathrm{nA} / \mathrm{ms}$ in slices from juvenile mice ( $n=158$ events; Fig. $4 D$ ). The greater charge transfer we saw for cPSCs in 4-AP compared to
cEPSCs likely reflects the additional contribution of inhibitory PSCs, which are depolarizing in our low chloride internal solution. In summary, hippocampal slices from juvenile and adult mice can generate cPSCs that are qualitatively similar, but slices from adult mice are less 


\section{A cEPSCs evoked following $\mathrm{GABA}_{\mathrm{A}} \mathrm{R}$ blockade}
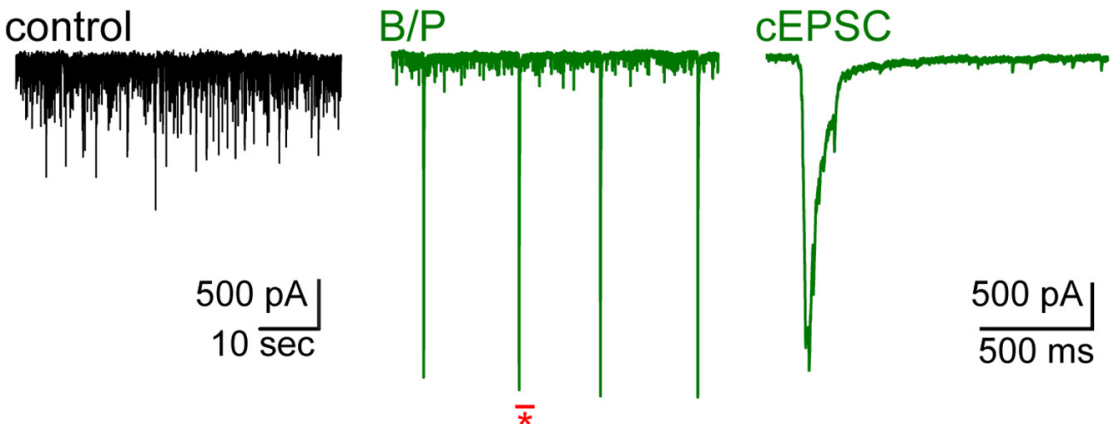

B cPSCs evoked by 4-AP

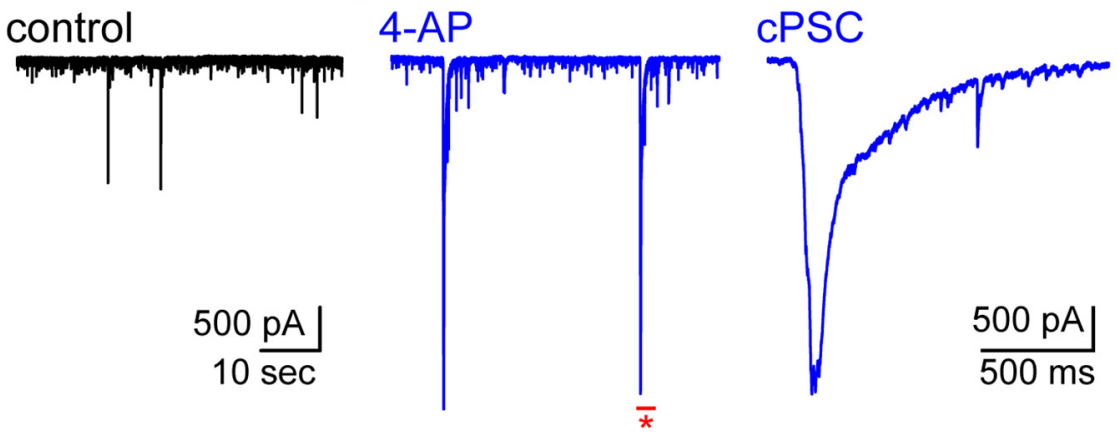

\section{C cPSC frequency}

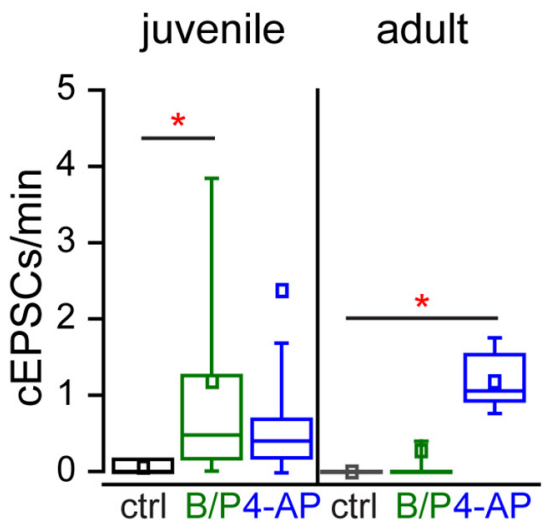

\section{D cPSC charge transfer}

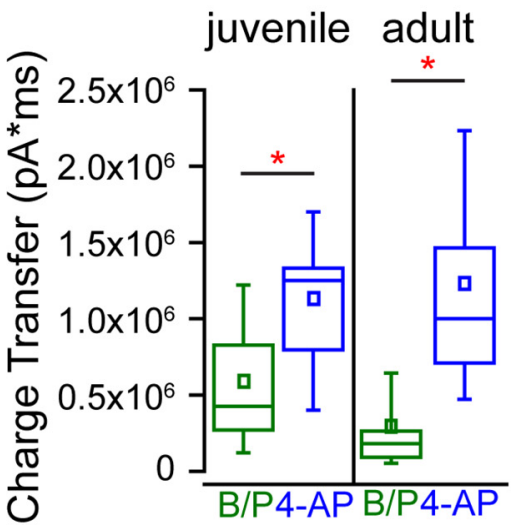

Figure 4. Pharmacological disruption of the hippocampal network leads to cPSCs in HMCs. A, Example traces showing spontaneous synaptic activity in a HMC in ACSF (black), and following addition of bicuculline and picrotoxin (B/P: GABA $R$ antagonists; green). Expanded portion of the trace on the right shows a cEPSC recorded following addition of bicuculline and picrotoxin. $\boldsymbol{B}$, Example traces showing spontaneous synaptic activity in a HMC in ACSF (black), and following addition of 4-AP (blue). Expanded portion of the trace on the right shows a cEPSC recorded following addition of 4-AP. C, cPSC frequencies in different pharmacological conditions in HMCs recorded in slices from juvenile (left) and adult (right) mice. $\boldsymbol{D}$, cPSC charge transfers recorded in different pharmacological conditions in slices from juvenile (left) and adult (right) mice.

likely to develop cEPSCs in disinhibited conditions than are slices from juvenile mice.

We differentiated the DG or CA3 as the origin of synchronized input that generated compound bursts by either reducing release probability at MF synapses with DCG-IV or by lesioning slices at the CA3-hilar border. In slices disinhibited with $\mathrm{GABA}_{\mathrm{A}}$ receptor antagonists, bath application of DCG-IV did not alter cEPSC frequency in HMC recordings from juvenile or adult mice (juvenile: 1.65 $\pm 0.35 \mathrm{cEPSC} / \mathrm{min}, n=18$ from 12 animals, $p=0.40$ compared to data from Fig. $4 C$; adult: $0.43 \pm 0.28$ cEP-
$\mathrm{SCs} / \mathrm{min}, n=17$ from 11 animals, $p=0.73$; Fig. $5 A, B$ ). To test whether CEPSCs originated in CA3, acute slices were prepared, in which a cut was made between the tips of the two blades of the dentate gyrus to separate the hilus from CA3 pyramidal neurons. No cEPSCs were observed in HMC recordings from cut slices $(n=8$ recordings from four animals; Fig. $5 D, E$ ). In contrast to cEPSCs, individual synaptic currents (sEPSCs) were reduced by application of DCG-IV in recordings from slices prepared from both juvenile and adult mice (juvenile: control, $11.0 \pm 2.2 \mathrm{~Hz}$; DCG-IV, $4.85 \pm 0.85 \mathrm{~Hz} ; n=13$ from seven animals, $p=$ 
A Intact Slices
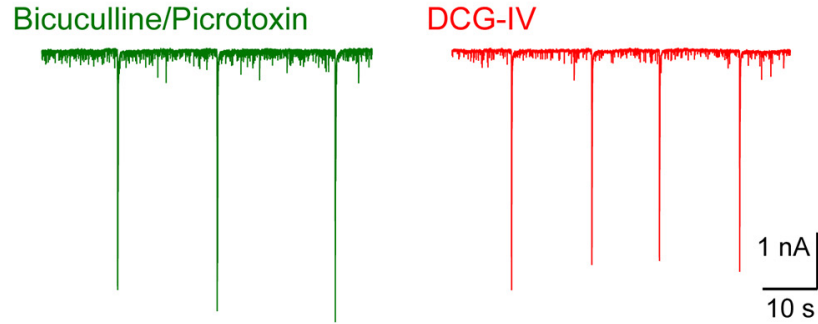

B cEPSC frequency

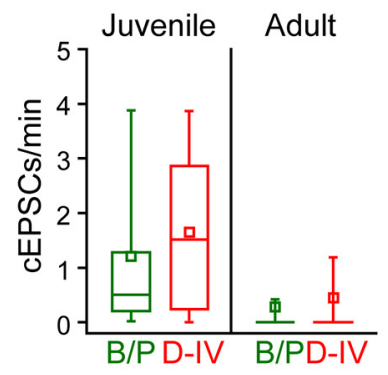

C sEPSC frequency

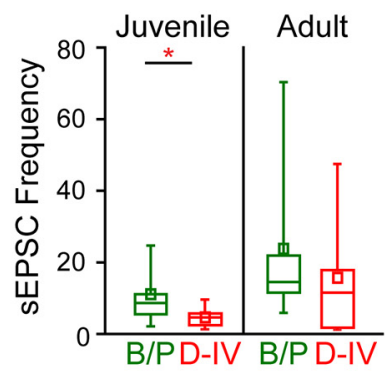

\section{Dissected Slices}

Bicuculline/Picrotoxin

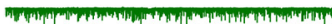

\section{E cEPSC frequency}

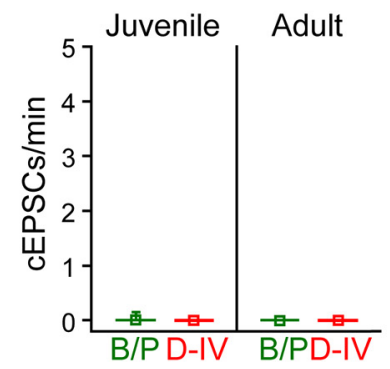

F sEPSC frequency

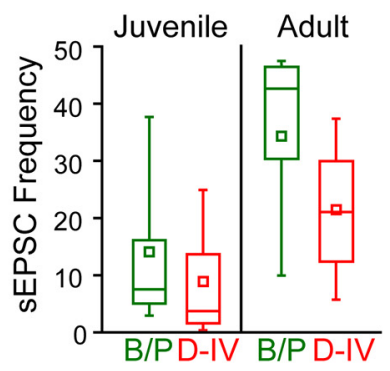

Figure 5. cPSCs propagate to HMCs from CA3. A, Example traces showing CPSCs recorded in HMCs in the presence of bicuculline and picrotoxin (green) and after addition of DCG-IV (red). B, cEPSC frequency in different pharmacological conditions in HMCs from juvenile (left) and adult (right) mice. C, sEPSC frequency in different pharmacological conditions in HMCs from juvenile (left) and adult (right) mice. $\boldsymbol{D}$, Example traces showing lack of cPSCs in slices where CA3 was dissected away from the hilus. $\boldsymbol{E}$, cEPSC frequency in HMCs from juvenile (left) and adult (right) mice. $\boldsymbol{F}$, sEPSC frequency in HMCs from juvenile (left) and adult (right) mice.

0.004; adult: control, $23.8 \pm 8.5 \mathrm{~Hz}$; DCG-IV, $13.6 \pm 5.1$ $\mathrm{Hz} ; n=11$ from seven animals, $p=0.03$ ). Separation from CA3 did not measurably alter HMC sEPSC frequencies compared to recordings from uncut slices (juvenile: in bicuculline/picrotoxin, $14.1 \pm 5.7 \mathrm{~Hz}$; DCG-IV, $9.0 \pm 3.9$ $\mathrm{Hz} ; n=8$ from four animals, $p=0.47$; adult: in bicuculline/picrotoxin, $34.6 \pm 10.2 \mathrm{~Hz}$; DCG-IV, $21.1 \pm 10.3 \mathrm{~Hz}$; $n=4$ from two animals, $p=0.41$; Fig. $5 C, F)$. These data therefore establish the CA3 as the origin of the synaptic bursts and are consistent with the proposal from earlier studies that synchronized firing in the CA3 is effectively

\section{A EEG}

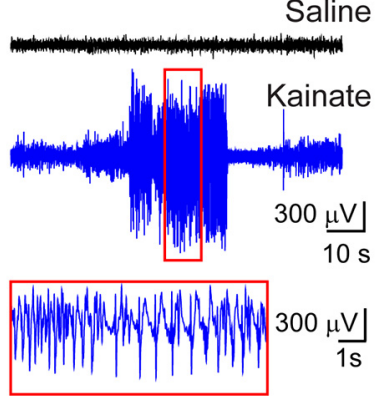

C cPSC frequency

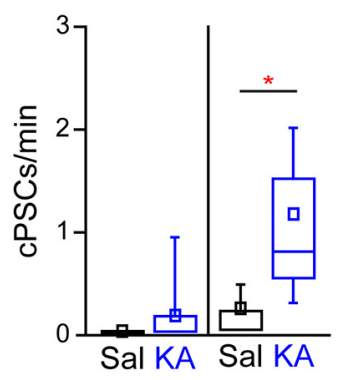

B Whole cell recordings (inhibition blocked)

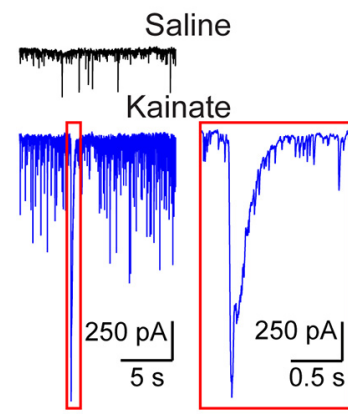

D cPSC charge transfer

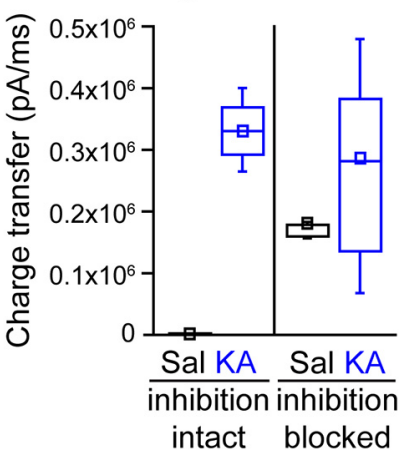

Figure 6. CPSCs are present in mice with chronic, spontaneous seizures. $\boldsymbol{A}$, Example EEG traces from mice injected intrahippocampally with saline (black) or KA (blue). Example from KAinjected mouse shows a spontaneous seizure with inset showing $10 \mathrm{~s}$ of the seizure event. $\boldsymbol{B}$, Whole-cell recordings of HMCs in acute slices from mice injected intrahippocampally with saline (black) or KA (blue) in the presence of $\mathrm{GABA}_{A} \mathrm{R}$ antagonists bicuculline and picrotoxin. Expanded portion of the trace from the KA-injected mouse shows a cEPSC (right). C, CPSC frequencies in HMCs in acute slices from intrahippocampally injected mice shows an increase in cPSCs in KA-injected mice following addition of bicuculline and picrotoxin. $\boldsymbol{D}$, CPSC charge transfers in HMCs from intrahippocampally injected mice. Note: no cPSCs were observed in saline-injected mice before the addition of bicuculline and picrotoxin.

propagated to mossy cells in the hilus (Scharfman, 1994a; Scharfman et al., 2001).

\section{cPSCs propagate to HMCs in epileptic mice}

To determine whether HMC cPSCs are present in mice with spontaneous convulsions, we induced chronic, spontaneous seizures in adult mice by intrahippocampal KA injection. Adult mice were injected with $100 \mathrm{nl}$ of either saline or $20 \mathrm{mM} \mathrm{KA}$. Two weeks following injections, all six KA-injected mice displayed visible seizures; none of the five control mice had seizures. EEG recordings from three mice in each condition confirmed the presence of electrographic seizures in KA- but not saline-injected mice; representative traces are shown in Figure $6 A$. We then prepared hippocampal slices from the mice and recorded cPSCs and cEPSCs from HMCs. Compound bursts of synaptic events were present before the addition of $\mathrm{GABA}_{\mathrm{A}}$ receptor antagonists in three of $12 \mathrm{HMCs}$ from $\mathrm{KA}$-injected mice (at a frequency of $0.05 \pm 0.02$ events/ min, cPSC charge transfer: $165 \pm 18 \mathrm{nA} / \mathrm{ms}$ ); none of the 
recordings from saline-injected mice contained cPSCs (Fig. 6B-D). Disinhibition of the slices elicited cEPSCs in 11 of 12 HMCs from mice injected with KA but only three of 12 saline-injected mice; in those neurons with cEPSCs, the frequency of events was higher in epileptic group (KA-injected frequency: $1.1 \pm 0.3$ events $/ \mathrm{min}$; salineinjected frequency: $0.20 \pm 0.14$ events $/ \mathrm{min}, p=0.01$; Fig. $6 B, C)$. There was no difference in sEPSC frequency or amplitude in $\mathrm{HMC}$ recordings from $\mathrm{KA}$ - or saline-injected mice (KA group: $13.8 \pm 2.4 \mathrm{~Hz}$, amplitude: $71 \pm 7 \mathrm{pA}, n=$ 12; saline group: $11.5 \pm 2.4 \mathrm{~Hz}, 66 \pm 9 \mathrm{pA}, n=11$ ). Thus, intrahippocampal KA injection leads to increased bursts of synchronized input to HMCs arising from hyperexcitability of the CA3 network.

\section{Discussion}

The current study was motivated by the surprising paucity of information regarding fundamental components of excitatory synapses on HMCs under physiologic and pathologic conditions. In particular, back-projections from CA3 to HMCs were described several decades ago but have not been examined functionally to the same extent as other synaptic contacts made by CA3 pyramidal neuron collaterals (Scharfman, 2016). This report provides new information on the receptor complement and shortterm plasticity at CA3-HMC synapses and contrasts those parameters with MF inputs to HMCs. We also determined that synchronized firing of CA3 neurons produces strongly depolarizing bursts of excitatory events in hyperexcitable conditions, underscoring the potential strength of the back-projection from CA3 to HMCs. Our data provide essential insight into basic aspects of connectivity that will be of use in explorations of the role of this circuit in cognition and in epileptic states.

\section{The CA3 back-projection to HMCs}

The back-projection from CA3 pyramidal neurons to HMCs has been hypothesized to be important for information processing in the hippocampus, providing a means for CA3 neurons to integrate input from perforant path projections and recurrent CA3 networks and to shape dentate excitability (Scharfman, 2007). The CA3 back-projections to the hilus play a crucial role in functions such as pattern completion and pattern separation (Lisman, 1999; Myers and Scharfman, 2009, 2011; Senzai and Buzsáki, 2017). Despite the potential importance of this projection, this synapse is relatively understudied compared to those between other principal neurons in the hippocampus (Scharfman, 1993b, 1994a). We found that CA3 synapses onto HMCs share properties with their analogous synapses on CA3 pyramidal neurons, exhibiting a substantial NMDA receptor component, an absence of postsynaptic kainate receptors, and modest degrees of short-term facilitation at low stimulation frequencies (Debanne et al., 1996; Castillo et al., 1997; Debanne et al., 1998; Perez-Rosello et al., 2011). CA3 pyramidal neurons often fire in bursts of action potentials in vivo (Tropp Sneider et al., 2006); facilitation at CA3-HMC synapses therefore suggests that CA3 pyramidal neurons have the potential to shape $\mathrm{HMC}$ activity during burst firing despite their modest unitary conductances. NMDA receptor- mediated currents at this synapse were prominent compared to MF synapses, and thus the back-projection from CA3 to HMCs is primed for conventional NMDA receptordependent long-term potentiation. The precise mechanisms of activity-dependent potentiation, such as whether they exhibit the unusual form of spike-timing-dependent plasticity discovered recently at CA3-CA3 synapses (Mishra et al., 2016), remain to be explored. In vivo work suggests that HMCs are highly active during behavior (Henze and Buzsáki, 2007; Danielson et al., 2017; Senzai and Buzsáki, 2017), whereas granule cells (Mistry et al., 2011; Danielson et al., 2016) have very sparse firing, suggesting that the back-projection from $\mathrm{CA} 3$, rather than the MF input, may be a principal driver of $\mathrm{HMC}$ activation in vivo.

\section{Shared and contrasting features of MF-HMC and MF-CA3 synapses}

Like MF-CA3 synapses, MF-HMC synapses are formed by MF giant synaptic boutons that are opposed to "thorny excrescences" on proximal dendrites (Frotscher et al., 1991; Kunkel et al., 1993). Recordings at MF-HMC synapses in rat suggest that they are physiologically similar to MF-CA3 synapses (Acsády et al., 1998; Lysetskiy et al., 2005). Surprisingly, in mice, we found that MF-HMC EPSCs did not facilitate to the same degree as those at MF-CA3 synapses (Salin et al., 1996; Henze et al., 2000; Fernandes et al., 2015). In CA3 pyramidal neurons, the MF input has been described as a "conditional detonator"; strong depolarization of pyramidal neurons occurs at higher frequencies or bursts of stimulation, in which the facilitation of MF glutamate release outweighs the feedforward inhibition mediated by CA3 interneurons (Urban et al., 2001; Henze et al., 2002; Mori et al., 2004). The lower degree of facilitation at HMC synapses suggests that MFs might not serve an equivalent function, although we note that a more robust facilitation in rat recordings was reported previously (Lysetskiy et al., 2005), suggesting there could be species-dependent variability. Anatomic differences between MF-HMC and MF-CA3 synapses also might contribute to these differences: while MF-CA3 synapses are thought to be exclusively at CA3 thorny excrescences, MF-HMC synapses are likely a mixture of similar complex synapses that innervate HMC thorny excrescences but also small terminals that innervate the distal dendrites (Acsády et al., 1998). It is possible that bouton and non-bouton MF synapses express different degrees of short-term plasticity. Alternatively, the relatively low level of facilitation could arise from the absence at MF-HMC synapses of presynaptic kainate receptors (Scott et al., 2008), which increase release probability when activated by endogenous release of glutamate at MF-CA3 pyramidal synapses (Contractor et al., 2001; Schmitz et al., 2001).

With respect to the postsynaptic complement of iGluRs, MF synapses on HMCs were similar to those on CA3 pyramidal neurons. The NMDA/AMPA ratio was low, and the EPSCs contained a kainate receptor component with slow kinetics of activation and decay similar to the

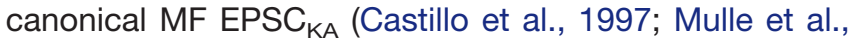


1998). The slow time course of decay of postsynaptic kainate receptors prolongs depolarization with sustained stimulation and alters temporal integration and spike firing in CA3 pyramidal neurons (Sachidhanandam et al., 2009; Pinheiro et al., 2013), and likely subserve the same function at MF synapses in HMCs. The presence of postsynaptic NMDA receptors similarly raises the possibility that MF-HMC synapses might express forms of LTP and metaplasticity that have been discovered only recently at MF-CA3 synapses (Kwon and Castillo, 2008; Rebola et al., 2008; Rebola et al., 2011), in addition to the classic presynaptic form of MF LTP (Zalutsky and Nicoll, 1990; Lysetskiy et al., 2005).

\section{Synaptic inputs in hyperexcitable conditions}

An objective of this study was to determine how synaptic input to HMCs is altered in conditions of hyperexcitability. We found that large-amplitude cEPSCs occurred spontaneously during our recordings, similar to burst discharges recorded in previous work from epileptic rats (Scharfman, 1994a; Scharfman et al., 2001; Myers and Scharfman, 2009, 2011). Synchronized bursting in CA3 occurs in hyperexcitable states (Scharfman, 1994a; McCloskey and Scharfman, 2011), and the development of these bursts is associated with oscillatory rhythms present in both humans with epilepsy and in rodent models (Zijlmans et al., 2009; Jefferys et al., 2012). We confirmed that CEPSCs observed in HMCs originate in CA3 and that these synchronous bursts were enhanced in hyperexcitable conditions, with the generation of compound bursts following disinhibition as well as when the $\mathrm{K}^{+}$channel blocker 4-AP was applied. The backprojection between $\mathrm{CA} 3$ and HMCs thus has the potential to powerfully shape hilar excitability through transmission of synchronous activity to the dentate gyrus.

Synchronized burst discharges from CA3 directly impact HMC excitability but also have to potential to converge on interneuron populations that provide inhibitory tone on HMCs. Recent work suggests that CA3 has relatively sparse recurrent connectivity in microcircuits (Guzman et al., 2016). The net effect of increased excitability will therefore likely depend in part on the connectivity and innervation patterns of these small circuits of synchronized CA3 pyramidal neurons, and the direct effect on the DG will be highly dependent on whether a particular microcircuit has its predominant actions on hilar interneuron or HMCs. During hyperexcitable states such as epilepsy where hilar interneuron populations are altered, this network activity is likely altered, changing the balance of excitatory drive to the dentate gyrus. Structural adaptations in one or more populations of hilar neurons also could contribute to hyperexcitability, similar to what occurs in CA1 pyramidal neurons and DGCs in a rodent model of febrile status epilepticus (Patterson et al., 2017).

Earlier work has found that synchronous events in the hippocampus are more prolonged in juvenile mice than in adult mice (Shao and Dudek, 2009). We similarly found differences in cPSCs recorded in HMCs with age as they were readily evoked by network disinhibition in juvenile but not in adult animals. Application of 4-AP, however, led to the generation of cEPSCs in both juvenile and adult mice. There is evidence that 4-AP causes synchronous firing of hippocampal interneurons, particularly hilar interneurons, in acute slices (Fueta and Avoli, 1992; Grosser et al., 2014; Avoli and Jefferys, 2016), suggesting perhaps that these synchronous events are driven in part by altered activity of hilar interneurons and may be a factor in the enhanced seizure susceptibility of immature brains (Rakhade and Jensen, 2009). Since pathologic network synchrony, in the form of cPSCs, was enhanced in adult mice following intrahippocampal KA injection and after the generation of spontaneous seizures, there could be a developmentally enhanced role of hippocampal inhibition in the adult mouse hippocampus that is disrupted following seizures.

No direct evaluation of the CA3-HMC synapse has been performed in the context of epilepsy; however, our results suggest that this synapse may be instrumental in propagating pathologic network activity through the hippocampus during epileptogenesis and be a driving force in HMC degeneration and dysfunction in TLE. HMCs that survive initial seizures might serve as a powerful epileptic focus by relaying pathologic synchronous activity from CA3 through the hilus to the dentate gyrus. We posit that the projection from CA3 to HMCs could play an important role not only in the healthy hippocampal circuit but in pathologic states such as epilepsy.

\section{References}

Acsády L, Kamondi A, Sík A, Freund T, Buzsáki G (1998) GABAergic cells are the major postsynaptic targets of mossy fibers in the rat hippocampus. J Neurosci 18:3386-3403. Medline

Amaral DG, Witter MP (1989) The three-dimensional organization of the hippocampal formation: a review of anatomical data. Neuroscience 31:571-591. Medline

Andersen P, Bliss TV, Skrede KK (1971) Lamellar organization of hippocampal pathways. Exp Brain Res 13:222-238. Medline

Avoli M, Jefferys JGR (2016) Models of drug-induced epileptiform synchronization in vitro. J Neurosci Methods 260:26-32. CrossRef Medline

Bekkers JM, Clements JD (1999) Quantal amplitude and quantal variance of strontium-induced asynchronous EPSCs in rat dentate granule neurons. J Physiol 516:227-248. CrossRef

Blümcke I, Suter B, Behle K, Kuhn R, Schramm J, Elger CE, Wiestler OD (2000) Loss of hilar mossy cells in Ammon's horn sclerosis. Epilepsia 41 [Suppl6]:S174-S180. Medline

Buckmaster PS, Schwartzkroin PA (1994) Hippocampal mossy cell function: a speculative view. Hippocampus 4:393-402. CrossRef Medline

Castillo PE, Malenka RC, Nicoll RA (1997) Kainate receptors mediate a slow postsynaptic current in hippocampal CA3 neurons. Nature 388:182-186. CrossRef Medline

Contractor A, Swanson GT, Heinemann SF (2001) Kainate receptors are involved in short and long term plasticity at mossy fiber synapses in the hippocampus. Neuron 29:209-216. Medline

Danielson NB, Turi GF, Ladow M, Chavlis S, Petrantonakis PC, Poirazi P, Losonczy A (2017) In vivo imaging of dentate gyrus mossy cells in behaving mice. Neuron 93:552-559. CrossRef Medline

Danielson NB, Kaifosh P, Zaremba JD, Lovett-Barron M, Tsai J, Denny CA, Balough EM, Goldberg AR, Drew LJ, Hen R, Losonczy A, Kheirbek MA (2016) Distinct contribution of adult-born hippocampal granule cells to context encoding. Neuron 90:101-112. CrossRef Medline 
Debanne D, Guérineau NC, Gähwiler BH, Thompson SM (1996) Paired-pulse facilitation and depression at unitary synapses in rat hippocampus: quantal fluctuation affects subsequent release. $J$ Physiol 491:163-176. CrossRef

Debanne D, Gähwiler BH, Thompson SM (1998) Long-term synaptic plasticity between pairs of individual CA3 pyramidal cells in rat hippocampal slice cultures. J Physiol 507:237-247. CrossRef

Fernandes HB, Riordan S, Nomura T, Remmers CL, Kraniotis S, Marshall JJ, Kukreja L, Vassar R, Contractor A (2015) Epac2 mediates cAMP-dependent potentiation of neurotransmission in the hippocampus. J Neurosci 35:6544-6553. CrossRef Medline

Frotscher M, Seress L, Schwerdtfeger WK, Buhl E (1991) The mossy cells of the fascia dentata: a comparative study of their fine structure and synaptic connections in rodents and primates. $J$ Comp Neur 312:145-163. CrossRef Medline

Fueta Y, Avoli M (1992) Effects of antiepileptic drugs on 4-aminopyridine-induced epileptiform activity in young and adult rat hippocampus. Epilepsy Res 12:207-215. CrossRef

Grosser S, Queenan BN, Lalchandani RR, Vicini S (2014) Hilar somatostatin interneurons contribute to synchronized GABA activity in an in vitro epilepsy model. PLoS One 9:e86250. CrossRef

Guzman SJ, Schlögl A, Frotscher M, Jonas P (2016) Synaptic mechanisms of pattern completion in the hippocampal CA3 network. Science 353:1117-1123. CrossRef Medline

Henze DA, Buzsáki G (2007) Hilar mossy cells: functional identification and activity in vivo. Prog Brain Res 163:199-216.

Henze DA, Urban NN, Barrionuevo G (2000) The multifarious hippocampal mossy fiber pathway: a review. Neuroscience 98:407427. Medline

Henze DA, Wittner L, Buzsáki G (2002) Single granule cells reliably discharge targets in the hippocampal CA3 network in vivo. Nat Neurosci 5:790-795. CrossRef Medline

Heuermann RJ, Jaramillo TC, Ying SW, Suter BA, Lyman KA, Han Y, Lewis AS, Hampton TG, Shepherd GMG, Goldstein PA, Chetkovich DM (2016) Reduction of thalamic and cortical Ih by deletion of TRIP8b produces a mouse model of human absence epilepsy. Neurobiol Dis 85:81-92. CrossRef Medline

Hubbard JA, Szu JI, Yonan JM, Binder DK (2016) Regulation of astrocyte glutamate transporter-1 (GLT1) and aquaporin-4 (AQP4) expression in a model of epilepsy. Exp Neurol 283:85-96. CrossRef

Ishizuka N, Weber J, Amaral DG (1990) Organization of intrahippocampal projections originating from CA3 pyramidal cells in the rat. J Comp Neur 295:580-623. CrossRef

Jefferys JGR, Menendez de la Prida L, Wendling F, Bragin A, Avoli M, Timofeev I, Lopes da Silva FH (2012) Mechanisms of physiological and epileptic HFO generation. Prog Neurobiol 98:250-264. CrossRef Medline

Kunkel DD, Strowbridge BW, Anderson NL, Schwartzkroin PA (1993) Anatomical evidence for reciprocal connections between CA3 pyramidal cells and dentate mossy cells. Soc Neurosci Abstr 19:351.

Kwon HB, Castillo PE (2008) Long-term potentiation selectively expressed by NMDA receptors at hippocampal mossy fiber synapses. Neuron 57:108-120. CrossRef Medline

Larimer P, Strowbridge BW (2008) Nonrandom local circuits in the dentate gyrus. J Neurosci 28:12212-12223. CrossRef Medline

Lawrence JJ, Grinspan ZM, McBain CJ (2004) Quantal transmission at mossy fibre targets in the CA3 region of the rat hippocampus. $J$ Physiol 554:175-193. CrossRef Medline

Li XG, Somogyi P, Ylinen A, Buzsáki G (1994) The hippocampal CA3 network: an in vivo intracellular labeling study. J Comp Neur 339:181-208. CrossRef Medline

Lisman JE (1999) Relating hippocampal circuitry to function: recall of memory sequences by reciprocal dentate-CA3 interactions. Neuron 22:233-242. Medline

Lysetskiy M, Földy C, Soltesz I (2005) Long- and short-term plasticity at mossy fiber synapses on mossy cells in the rat dentate gyrus. Hippocampus 15:691-696. CrossRef Medline
Marchal C, Mulle C (2004) Postnatal maturation of mossy fibre excitatory transmission in mouse CA3 pyramidal cells: a potential role for kainate receptors. J Physiol 561:27-37. CrossRef Medline

Margerison JH, Corsellis JA (1966) Epilepsy and the temporal lobes. A clinical, electroencephalographic and neuropathological study of the brain in epilepsy, with particular reference to the temporal lobes. Brain 89:499-530. Medline

McCloskey DP, Scharfman HE (2011) Progressive, potassiumsensitive epileptiform activity in hippocampal area CA3 of pilocarpine-treated rats with recurrent seizures. Epilepsy Res 97: 92-102. CrossRef Medline

Mishra RK, Kim S, Guzman SJ, Jonas P (2016) Symmetric spike timing-dependent plasticity at CA3-CA3 synapses optimizes storage and recall in autoassociative networks. Nat Commun 7:11552. CrossRef Medline

Mistry R, Dennis S, Frerking M, Mellor JR (2011) Dentate gyrus granule cell firing patterns can induce mossy fiber long-term potentiation in vitro. Hippocampus 21:1157-1168. CrossRef Medline

Mori M, Abegg MH, Gähwiler BH, Gerber U (2004) A frequencydependent switch from inhibition to excitation in a hippocampal unitary circuit. Nature 431:453-456. CrossRef

Mulle C, Sailer A, Pérez-Otaño I, Dickinson-Anson H, Castillo PE, Bureau I, Maron C, Gage FH, Mann JR, Bettler B, Heinemann SF (1998) Altered synaptic physiology and reduced susceptibility to kainate-induced seizures in GluR6-deficient mice. Nature 392: 601-605. CrossRef Medline

Myers CE, Scharfman HE (2009) A role for hilar cells in pattern separation in the dentate gyrus: a computational approach. Hippocampus 19:321-337. CrossRef

Myers CE, Scharfman HE (2011) Pattern separation in the dentate gyrus: a role for the CA3 backprojection. Hippocampus 21:11901215. CrossRef Medline

Nahir B, Bhatia C, Frazier CJ (2007) Presynaptic inhibition of excitatory afferents to hilar mossy cells. J Neurophysiol 97:4036-4047. CrossRef Medline

Patterson KP, Barry JM, Curran MM, Singh-Taylor A, Brennan G, Rismanchi N, Page M, Noam Y, Holmes GL, Baram TZ (2017) Enduring memory impairments provoked by developmental febrile seizures are mediated by functional and structural effects of neuronal restrictive silencing factor. J Neurosci 37:3799-3812. CrossRef

Perez-Rosello T, Baker JL, Ferrante M, Iyengar S, Ascoli GA, Barrionuevo $G$ (2011) Passive and active shaping of unitary responses from associational/commissural and perforant path synapses in hippocampal CA3 pyramidal cells. J Comput Neurosci 31:159182. CrossRef Medline

Pinheiro PS, Lanore F, Veran J, Artinian J, Blanchet C, Crépel V, Perrais D, Mulle C (2013) Selective block of postsynaptic kainate receptors reveals their function at hippocampal mossy fiber synapses. Cereb Cortex 23:323-331. CrossRef Medline

Racine RJ (1972) Modification of seizure activity by electrical stimulation. II. Motor seizure. Electroencephalogr Clin Neurophysiol 32:281-294. Medline

Rakhade SN, Jensen FE (2009) Epileptogenesis in the immature brain: emerging mechanisms. Nat Rev Neurol 5:380-391. CrossRef Medline

Rebola N, Lujan R, Cunha RA, Mulle C (2008) Adenosine A2A receptors are essential for long-term potentiation of NMDA-EPSCs at hippocampal mossy fiber synapses. Neuron 57:121-134. CrossRef Medline

Rebola N, Carta M, Lanore F, Blanchet C, Mulle C (2011) NMDA receptor-dependent metaplasticity at hippocampal mossy fiber synapses. Nat Neurosci 14:691-693. CrossRef Medline

Sachidhanandam S, Blanchet C, Jeantet Y, Cho YH, Mulle C (2009) Kainate receptors act as conditional amplifiers of spike transmission at hippocampal mossy fiber synapses. J Neurosci 29:50005008. CrossRef Medline

Salin PA, Scanziani M, Malenka RC, Nicoll RA (1996) Distinct shortterm plasticity at two excitatory synapses in the hippocampus. Proc Natl Acad Sci USA 93:13304-13309. Medline 
Santhakumar V, Aradi I, Soltesz I (2005) Role of mossy fiber sprouting and mossy cell loss in hyperexcitability: a network model of the dentate gyrus incorporating cell types and axonal topography. $J$ Neurophysiol 93:437-453. CrossRef Medline

Scharfman HE (1993a) Activation of dentate hilar neurons by stimulation of the fimbria in rat hippocampal slices. Neurosci Lett 156: 61-66.

Scharfman HE (1993b) Characteristics of spontaneous and evoked EPSPs recorded from dentate spiny hilar cells in rat hippocampal slices. J Neurophysiol 70:742-757.

Scharfman HE (1994a) Synchronization of area CA3 hippocampal pyramidal cells and non-granule cells of the dentate gyrus in bicuculline-treated rat hippocampal slices. Neuroscience 59:245257.

Scharfman HE (1994b) Evidence from simultaneous intracellular recordings in rat hippocampal slices that area CA3 pyramidal cells innervate dentate hilar mossy cells. J Neurophysiol 72:2167-2180.

Scharfman HE (2007) The CA3 "backprojection" to the dentate gyrus. Prog Brain Res 163:627-637. CrossRef Medline

Scharfman HE (2016) The enigmatic mossy cell of the dentate gyrus. Nat Rev Neurosci 17:562-575. CrossRef Medline

Scharfman HE, Schwartzkroin PA (1988) Electrophysiology of morphologically identified mossy cells of the dentate hilus recorded in guinea pig hippocampal slices. J Neurosci 8:3812-3821. Medline

Scharfman HE, Myers CE (2012) Hilar mossy cells of the dentate gyrus: a historical perspective. Front Neural Circuits 6:106. CrossRef Medline

Scharfman HE, Smith KL, Goodman JH, Sollas AL (2001) Survival of dentate hilar mossy cells after pilocarpine-induced seizures and their synchronized burst discharges with area CA3 pyramidal cells. Neuroscience 104:741-759. Medline

Schmitz D, Mellor J, Nicoll RA (2001) Presynaptic kainate receptor mediation of frequency facilitation at hippocampal mossy fiber synapses. Science 291:1972-1976. CrossRef Medline

Scott R, Lalic T, Kullmann DM, Capogna M, Rusakov DA (2008) Target-cell specificity of kainate autoreceptor and $\mathrm{Ca}^{2+}$-storedependent short-term plasticity at hippocampal mossy fiber synapses. J Neurosci 28:13139-13149. CrossRef Medline

Senzai Y, Buzsáki G (2017) Physiological properties and behavioral correlates of hippocampal granule cells and mossy cells. Neuron 93:691-704. CrossRef Medline
Shao L-R, Dudek FE (2009) Both synaptic and intrinsic mechanisms underlie the different properties of population bursts in the hippocampal CA3 area of immature versus adult rats. J Physiol 587:5907-5923. CrossRef Medline

Sloviter RS (1987) Decreased hippocampal inhibition and a selective loss of interneurons in experimental epilepsy. Science 235:73-76. CrossRef

Sloviter RS (1989) Calcium-binding protein (calbindin-D28k) and parvalbumin immunocytochemistry: localization in the rat hippocampus with specific reference to the selective vulnerability of hippocampal neurons to seizure activity. J Comp Neur 280:183196. CrossRef Medline

Sloviter RS, Zappone CA, Harvey BD, Bumanglag AV, Bender RA, Frotscher M (2003) "Dormant basket cell" hypothesis revisited: relative vulnerabilities of dentate gyrus mossy cells and inhibitory interneurons after hippocampal status epilepticus in the rat. $J$ Comp Neur 459:44-76. CrossRef

Tropp Sneider J, Chrobak JJ, Quirk MC, Oler JA, Markus EJ (2006) Differential behavioral state-dependence in the burst properties of CA3 and CA1 neurons. Neuroscience 141:1665-1677. CrossRef Medline

Urban NN, Henze DA, Barrionuevo G (2001) Revisiting the role of the hippocampal mossy fiber synapse. Hippocampus 11:408-417. CrossRef Medline

Wenzel HJ, Buckmaster PS, Anderson NL, Wenzel ME, Schwartzkroin PA (1997) Ultrastructural localization of neurotransmitter immunoreactivity in mossy cell axons and their synaptic targets in the rat dentate gyrus. Hippocampus 7:559-570. CrossRef Medline

Zalutsky RA, Nicoll RA (1990) Comparison of two forms of long-term potentiation in single hippocampal neurons. Science 248:16191624. Medline

Zhang W, Thamattoor AK, LeRoy C, Buckmaster PS (2015) Surviving mossy cells enlarge and receive more excitatory synaptic input in a mouse model of temporal lobe epilepsy. Hippocampus 25:594604. CrossRef

Zijlmans M, Jacobs J, Zelmann R, Dubeau F, Gotman J (2009) High-frequency oscillations mirror disease activity in patients with epilepsy. Neurology 72:979-986. CrossRef Medline 